\title{
KAJIAN PEMODELAN DERET WAKTU NONLINIER THRESHOLD AUTOREGRESSIVE (TAR)
}

\author{
Puji Noviandari \\ Universitas Jenderal Soedirman \\ veeyan_love18@yahoo.com \\ Renny \\ Universitas Jenderal Soedirman \\ renny_shajako@yahoo.com
}

\begin{abstract}
Nonlinear time series are time series that are not stable due to a sudden jump. Nonlinear time series often found in financial data. Threshold Autoregressive (TAR) modeling is a time series modeling with a segmented autoregressive (AR)'s model such that among different regimes may have different AR model. This research studied how to obtain the Ordinary Least Square (OLS) estimator for TAR model and examine signification the OLS's estimator by using $t$ test. This research also studied the other stages of TAR modeling, which are nonlinearity test using Tsay test, TAR model identification by using arranged AR approach and Akaike's Information Criterion (AIC), and diagnostic test by examining the white noise properties and normality test on the residuals. As an illustration, the TAR modeling was applied on weekly data of rupiah exchange rate against US dollar for period October $4^{\text {th }} 2004$ to November $7^{\text {th }} 2011$. The result show that the best TAR model for the data is TAR $(2 ; 2,2 ; 1)$ with threshold value $r=9857$.
\end{abstract}

Keywords: Nonlinear time series, Threshold Autoregressive, Ordinary Least Square estimator, white noise.

ABSTRAK. Deret waktu nonlinier merupakan deret waktu yang tidak stabil akibat terjadinya lonjakan secara tiba-tiba. Deret waktu nonlinier sering dijumpai pada data finansial. Pemodelan deret waktu nonlinier Threshold Autoregressive (TAR) merupakan pemodelan deret waktu dengan model autoregressive (AR) tersegmen sehingga diantara regime (segmen) yang berbeda dimungkinkan untuk mempunyai model AR yang berbeda. Pada penelitian ini dipelajari cara memperoleh estimator Ordinary Least Square (OLS) pada model TAR dan cara menguji kesignifikanan dari estimator OLS menggunakan uji t. Kemudian dipelajari tahap-tahap lain dalam pemodelan TAR yaitu uji nonlinieritas melalui uji Tsay, identifikasi model TAR melalui pendekatan AR tersusun dan Akaike's Information Criterion (AIC), dan uji diagnostik melalui uji sifat white noise dan uji kenormalan pada residual. Sebagai contoh, pemodelan TAR diterapkan pada data mingguan kurs rupiah terhadap dollar Amerika Serikat periode 4 Oktober 2004 sampai dengan 7 Nopember 2011. Hasilnya menunjukkan bahwa model TAR terbaik untuk data tersebut adalah $\operatorname{TAR}(2 ; 2,2 ; 1)$ dengan nilai threshold $r=9857$.

Kata Kunci: Deret waktu nonlinier, Threshold Autoregressive, estimator Ordinary Least Square, white noise. 


\section{PENDAHULUAN}

Deret waktu merupakan serangkaian data pengamatan yang terjadi berdasarkan indeks waktu secara berurutan dengan interval waktu pengamatan tetap (Aswi dan Sukarna, 2006:5). Misalnya data bulanan curah hujan, data tahunan jumlah penduduk, data harian kurs, dan sebagainya. Menurut Makridakis dan McGee (1993) (dalam Nuryana, 2009:1), model-model deret waktu seperti Moving Average, Exponential Smoothing, Regresi Dummy, Holt dan Winter serta ARIMA Box-Jenkins adalah model-model yang sering digunakan untuk data yang mengandung hubungan linier.

Dalam praktek di lapangan, model-model linier tersebut seringkali tidak dapat menjelaskan data yang tidak stabil akibat terjadinya lonjakan secara tiba-tiba (kenaikan nilai secara tajam pada data). Data seperti ini sering dijumpai pada data finansial, seperti data saham, data inflasi, dan data kurs (Cryer dan Chan, 2008:384). Untuk mengatasi permasalahan tersebut, pemodelan deret waktu nonlinier diperkenalkan, salah satunya adalah pemodelan Threshold Autoregressive (TAR) yang dikenalkan oleh Howell Tong pada tahun 1978. Model TAR merupakan model autoregressive (AR) tersegmen sehingga diantara regime (segmen) yang berbeda dimungkinkan untuk mempunyai model AR yang berbeda. Oleh sebab itu, pada penelitian ini penulis tertarik untuk mengkaji pemodelan deret waktu nonlinier TAR.

Berdasarkan latar belakang tersebut, permasalahan yang muncul adalah bagaimana kajian dari pemodelan deret waktu nonlinier TAR dan bagaimana menggunakan pemodelan TAR pada data nyata. Pada penelitian ini, pemodelan TAR yang dikaji dibatasi hanya untuk kasus dua regime dan ditekankan pada kajian estimasi parameter model TAR. Penelitian ini mempunyai beberapa tujuan yaitu mengkaji pemodelan deret waktu nonlinier menggunakan model TAR dua regime dan mengilustrasikan pemodelan TAR pada data mingguan kurs rupiah terhadap dollar Amerika Serikat periode 4 Oktober 2004 sampai dengan 7 Nopember 2011. Manfaat yang diperoleh dari penelitian ini adalah hasil kajian pemodelan TAR dua regime diharapkan dapat digunakan sebagai acuan dasar untuk mempelajari pemodelan TAR dengan orde regime yang lebih tinggi dan 
ilustrasi pemodelan TAR pada data nyata diharapkan dapat memberikan gambaran bagaimana tahap-tahap dalam pemodelan TAR dilakukan.

\section{HASIL DAN PEMBAHASAN}

Model TAR yang paling sederhana adalah model TAR dengan dua regime, ditulis $\operatorname{TAR}\left(2 ; p_{1}, p_{2} ; d\right)$. Deret waktu $Z_{t}$ dikatakan mengikuti model TAR $\left(2 ; p_{1}, p_{2} ; d\right)$ apabila

$$
Z_{t}= \begin{cases}\phi_{0}^{(1)}+\sum_{q=1}^{p_{1}} \phi_{q}^{(1)} Z_{t-q}+a_{t}^{(1)}, & \text { jika } Z_{t-d}<r \\ \phi_{0}^{(2)}+\sum_{q=1}^{p_{2}} \phi_{q}^{(2)} Z_{t-q}+a_{t}^{(2)}, & \text { jika } Z_{t-d} \geq r\end{cases}
$$

(Cryer dan Chan, 2008:396).

Persamaan (1) menyatakan model TAR dengan dua regime dan satu threshold (nilai ambang batas) yaitu $r$. Regime pertama mengikuti model $\operatorname{AR}\left(p_{1}\right)$, regime kedua mengikuti model $\operatorname{AR}\left(p_{2}\right)$, dan parameter delay $d$ merupakan parameter yang mengindikasikan adanya kemungkinan bahwa lamanya adjustment process untuk terjadinya perubahan regime memerlukan lebih dari satu periode waktu (Permata, 2008:8). Misal $p=\operatorname{maks}\left\{p_{1}, p_{2}\right\}$, maka $d \leq p$.

\subsection{Estimasi Parameter Model TAR Menggunakan Metode Ordinary Least Square}

Model TAR $\left(2 ; p_{1}, p_{2} ; d\right)$ pada persamaan (1) merupakan model nonlinier, tetapi model ini dapat didekati oleh model linier dengan cara membuat dua model terpisah untuk masing-masing regime yaitu

$$
\begin{gathered}
Z_{t}^{(1)}=\phi_{0}^{(1)}+\phi_{1}^{(1)} Z_{t-1}+\ldots+\phi_{p_{1}}^{(1)} Z_{t-p_{1}}+a_{t}^{(1)}, \text { jika } Z_{t-d}<r \\
Z_{t}^{(2)}=\phi_{0}^{(2)}+\phi_{1}^{(2)} Z_{t-1}+\ldots+\phi_{p_{2}}^{(2)} Z_{t-p_{2}}+a_{t}^{(2)}, \text { jika } Z_{t-d} \geq r
\end{gathered}
$$

dengan:

$Z_{t}^{(j)} \quad=\quad$ pengamatan saat $t$ pada regime ke-j, $j=1,2$ 
$p_{j} \quad=\quad$ orde AR pada regime ke- $j, j=1,2$

$\phi_{0}^{(j)}, \phi_{1}^{(j)}, \ldots, \phi_{p_{j}}^{(j)}=$ parameter model TAR pada regime ke-j, $j=1,2\left(\phi_{0}^{(j)}\right.$ disebut juga parameter intersep)

$a_{t}^{(j)}=\quad$ error saat $t$ pada regime ke- $j$ yang berdistribusi $N\left(0, \sigma_{a}^{2}\right)$ dan antar $t$ yang berbeda bersifat saling bebas.

Dari persamaan (2) dan (3), model TAR dengan dua regime, secara umum dapat ditulis dengan

$$
Z_{t}^{(j)}=\phi_{0}^{(j)}+\phi_{1}^{(j)} Z_{t-1}+\ldots+\phi_{p_{j}}^{(j)} Z_{t-p_{j}}+a_{t}^{(j)}, \text { untuk } j=1,2
$$

Jika disusun dalam bentuk matriks, persamaan (4) menjadi

$$
\mathbf{Z}_{j}=\mathbf{X}_{j} \boldsymbol{\varphi}^{(j)}+\mathbf{a}_{j},
$$

dengan:

$\mathbf{Z}_{j} \quad=$ vektor variabel tak bebas $\left(Z_{p_{j}+1}^{(j)}, Z_{p_{j}+2}^{(j)}, \ldots, Z_{n}^{(j)}\right)^{t}$ berukuran $\left(n-p_{j}\right) \times 1$

$\boldsymbol{\varphi}^{(j)}=$ vektor parameter model TAR $\left(\phi_{0}^{(j)}, \phi_{1}^{(j)}, \ldots, \phi_{p_{j}}^{(j)}\right)^{t}$ berukuran $\left(p_{j}+1\right) \times 1$

$\mathbf{a}_{j} \quad=$ vektor $\operatorname{error}\left(a_{p+1}^{(j)}, a_{p+2}^{(j)}, \ldots, a_{n}^{(j)}\right)^{t}$ berukuran $\left(n-p_{j}\right) \times 1$

$\mathbf{X}_{j}=$ matriks variabel bebas berukuran $\left(n-p_{j}\right) \times\left(p_{j}+1\right)$.

Menurut prinsip metode Least Square, estimator OLS untuk parameter $\varphi^{(j)}$ adalah $\boldsymbol{\varphi}^{(j)}=\hat{\boldsymbol{\varphi}}^{(j)}$ yang dapat meminimumkan jumlah kuadrat error

$$
L\left(\boldsymbol{\varphi}^{(j)}\right)=\mathbf{a}_{j}^{t} \mathbf{a}_{j}=\left(\mathbf{Z}_{j}-\mathbf{X}_{j} \boldsymbol{\varphi}^{(j)}\right)^{t}\left(\mathbf{Z}_{j}-\mathbf{X}_{j} \boldsymbol{\varphi}^{(j)}\right) .
$$

Karena $L\left(\varphi^{(j)}\right)$ merupakan fungsi yang kontinu dan diferensiabel terhadap $\boldsymbol{\varphi}^{(j)}$, maka $\boldsymbol{\varphi}^{(j)}=\hat{\boldsymbol{\varphi}}^{(j)}$ dapat dicari dengan menyelesaikan persamaan $\frac{\partial L\left(\boldsymbol{\varphi}^{(j)}\right)}{\partial \boldsymbol{\varphi}^{(j)}}=0$.

Karena jumlah kuadrat error

$$
L\left(\boldsymbol{\varphi}^{(j)}\right)=\mathbf{Z}_{j}^{t} \mathbf{Z}_{j}-2\left(\mathbf{X}_{j}^{t} \mathbf{Z}_{j}\right)^{t} \boldsymbol{\varphi}^{(j)}+\left(\boldsymbol{\varphi}^{(j)}\right)^{t}\left(\mathbf{X}_{j}^{t} \mathbf{X}_{j}\right) \boldsymbol{\varphi}^{(j)},
$$

maka turunan pertamanya terhadap masing-masing elemen di $\varphi^{(j)}$ adalah 
$\frac{\partial L\left(\boldsymbol{\varphi}^{(j)}\right)}{\partial \boldsymbol{\varphi}^{(j)}}=-2 \mathbf{X}_{j}{ }^{t} \mathbf{Z}_{j}+2 \mathbf{X}_{j}{ }_{j} \mathbf{X}_{j} \boldsymbol{\varphi}^{(j)} . \quad$ Persamaan $\frac{\partial L\left(\boldsymbol{\varphi}^{(j)}\right)}{\partial \boldsymbol{\varphi}^{(j)}}=0$ ekuivalen dengan persamaan berikut:

$$
\left(\mathbf{X}_{j}^{t} \mathbf{X}_{j}\right) \boldsymbol{\varphi}^{(j)}=\mathbf{X}_{j}^{t} \mathbf{Z}_{j}
$$

Jika $\mathbf{X}_{j}{ }_{j} \mathbf{X}_{j} \quad$ nonsingular, maka solusi persamaan (6) adalah $\hat{\boldsymbol{\varphi}}^{(j)}=\left(\mathbf{X}_{j}^{t} \mathbf{X}_{j}\right)^{-1} \mathbf{X}_{j}^{t} \mathbf{Z}_{j}$. Jadi, estimator OLS untuk parameter $\boldsymbol{\varphi}^{(j)}$ adalah

$$
\hat{\boldsymbol{\varphi}}^{(j)}=\left(\mathbf{X}_{j}^{t} \mathbf{X}_{j}\right)^{-1} \mathbf{X}_{j}^{t} \mathbf{Z}_{j}, \quad \text { untuk } j=1,2 .
$$

Untuk menguji kesignifikanan dari estimator OLS dapat digunakan uji $t$ dengan statistik uji yang digunakan

$$
t_{\text {hitung }}=\frac{\hat{\boldsymbol{\varphi}}^{(j)}}{S E\left(\hat{\boldsymbol{\varphi}}^{(j)}\right)} .
$$

Estimator OLS dikatakan signifikan berbeda dengan nol jika $\left|t_{\text {hitung }}\right|>t_{\frac{\alpha}{2}, n-n_{p}}$ atau nilai- $p<\alpha$, dengan $\alpha=0,05, n$ merupakan banyaknya pengamatan, dan $n_{p}$ merupakan banyaknya parameter.

\subsection{Uji Nonlinieritas Menggunakan Uji Tsay}

Uji nonlinieritas adalah pengujian hipotesis untuk memeriksa apakah data deret waktu yang diteliti bersifat nonlinier atau tidak. Salah satu uji yang digunakan adalah uji Tsay (Chan, dkk, 2005:39). Uji Tsay merupakan uji deteksi nonlinieritas pada deret waktu yang menggunakan konsep orde AR tersusun dan predictive residuals. Statistik uji yang digunakan dalam uji Tsay adalah statistik $F$ yang didefinisikan sebagai

$$
\hat{F}(p, d)=\frac{\left(\sum_{r_{\min }+1}^{n-d-h+1} \hat{e}_{i}^{2}-\sum_{r_{\min }+1}^{n-d-h+1} \hat{\varepsilon}_{i}^{2}\right) /(p+1)}{\sum_{r_{\min }+1}^{n-d-h+1} \hat{e}_{i}^{2} /\left(n-d-h-r_{\min }-p\right)},
$$


dengan $h=\operatorname{maks}\{1, p+1-d\}$ dan $r_{\min } \approx(n / 10)+p$. Asumsi linieritas ditolak jika $\hat{F}(p, d)>F_{\alpha,\left(p+1, n-d-h-r_{\min }-p\right)}$ atau nilai- $p<\alpha$.

\subsection{Identifikasi Model TAR}

Prosedur pengidentifikasian model TAR berdasarkan pendekatan AR tersusun dan Akaike's Information Criterion (AIC).

a. Mengidentifikasi parameter delay

Misal $D=\{1,2, \ldots, p\}$ adalah himpunan yang anggotanya berpotensi untuk menjadi parameter delay $d$ dan $p$ adalah orde maksimum AR, maka untuk memilih nilai $d$ dari himpunan $D$ tersebut dapat dilakukan melalui statistik $F_{\text {hitung }}$ pada persamaan (7). Nilai $d$ yang dipilih adalah

$$
\hat{F}(p, \hat{d})=\operatorname{maks}_{d \in D}\{\hat{F}(p, \hat{d})\} .
$$

b. Mengidentifikasi himpunan yang anggotanya berpotensi menjadi nilai threshold

Misal $R=\left\{r_{1}, r_{2}, \ldots, r_{s}\right\}$ adalah himpunan yang anggotanya berpotensi untuk menjadi nilai threshold $r$, maka $R$ dapat dapat ditentukan melalui scatterplot antara $t$-ratio (statistik $t$ ) pada koefisien $\mathrm{AR}$ tersusun lag $d$ dengan $Z_{t-d}$. Berdasarkan scatterplot tersebut, dapat ditentukan $R$ yang membagi plot menjadi 2 regime sehingga tiap regime-nya merupakan deret waktu linier.

c. Mengidentifikasi orde model AR tiap regime

Berdasarkan nilai delay $d$ dan himpunan $R$ yang telah diketahui dan misal $p$ adalah order AR maksimum dari dua regime, maka dapat ditentukan orde model AR tiap regime melalui AIC. Orde model AR tiap regime disimbolkan dengan $p_{j}$, untuk $j=1,2$ dipilih berdasarkan AIC yaitu

$$
\operatorname{AIC}\left(\hat{p}_{j}\right)=\min _{0 \leq p_{j} \leq p}\left\{n_{j} \ln \left[\frac{\left\|\hat{\mathbf{a}}\left(p_{j}\right)\right\|^{2}}{n_{j}}\right]+2\left(p_{j}+1\right)\right\}
$$

dengan: 


$$
\begin{aligned}
n_{j}= & \text { jumlah pengamatan yang mengikuti model } \operatorname{AR}\left(p_{j}\right) \text { pada regime } \\
& \text { ke- } j \\
\hat{\mathbf{a}}\left(p_{j}\right)= & \text { vektor residual dari model } \operatorname{AR}\left(p_{j}\right), \text { dengan nilai }\left\|\hat{\mathbf{a}}\left(p_{j}\right)\right\| \text { adalah } \\
& \text { panjang vektor-vektor } \hat{\mathbf{a}}\left(p_{j}\right) .
\end{aligned}
$$

d. Mengidentifikasi nilai threshold

Setelah diketahui nilai $\operatorname{AIC}\left(\hat{p}_{j}\right)$, maka nilai threshold $r$ dapat ditentukan dengan menggunakan AIC yaitu

$$
\operatorname{AIC}(d, \hat{r})=\min _{r \in R}\{\operatorname{AIC}(d, r)\}
$$

dengan $\operatorname{AIC}(d, r)=\operatorname{AIC}\left(\hat{p}_{1}\right)+\operatorname{AIC}\left(\hat{p}_{2}\right)$.

\subsection{Uji Diagnostik}

Uji diagnostik merupakan uji yang digunakan untuk memeriksa kesesuaian asumsi-asumsi yang digunakan pada model TAR yaitu error dari model bersifat white noise (berdistribusi normal dengan mean nol, variansi konstan, dan antar pengamatan bersifat saling bebas). Karena error $a_{t}$ tidak pernah teramati, maka pengujian asumsi-asumsi untuk error $a_{t}$ dapat dilakukan pada residual model yaitu $\hat{a}_{t}=Z_{t}-\hat{Z}_{t}$, dengan $\hat{Z}_{t}$ merupakan prediksi dari pengamatan ke- $t$.

a) Uji Sifat White Noise pada Residual

Pengujian asumsi residual $\hat{a}_{t}$ mempunyai mean nol, variansi konstan, dan antar pengamatan tidak berkorelasi, dapat dilihat melalui diagram plot antara residual $\hat{a}_{t}$ dengan $t$. Jika fluktuasi residual standar terjadi di sekitar 0 dan bergerak di suatu kisaran nilai tertentu, maka dapat dikatakan bahwa asumsi mean nol dan variansi konstan pada model sudah terpenuhi. Pengujian asumsi antar pengamatan tidak berkorelasi dapat dilakukan melalui plot ACF sampel residual, ACF sampel residual didefinisikan sebagai 


$$
r_{k}=\frac{\sum_{t=1}^{n-k}\left(\hat{a}_{t}-\overline{\hat{a}}\right)\left(\hat{a}_{t+k}-\overline{\hat{a}}\right)}{\sum_{t=1}^{n}\left(\hat{a}_{t}-\overline{\hat{a}}\right)^{2}}, \quad \text { untuk } k=0,1,2, \ldots
$$

Jika semua nilai ACF sampel dari residual pada plot residual berada pada batas kritisnya yaitu lebih dari $95 \%$ nilai $r_{k}$ berada pada ambang batas $\pm \frac{1,96}{\sqrt{n}}$, dapat disimpulkan bahwa $E\left(\hat{a}_{t} \hat{a}_{t+k}\right)=0$ artinya residual $\hat{a}_{t}$ dan residual $\hat{a}_{t+k}$ tidak berkorelasi.

b) Uji Kenormalan pada Residual

Pengujian asumsi residual $\hat{a}_{t}$ berdistribusi normal dapat dilakukan melalui histogram residual yang didukung oleh plot probability normal (Q-Q plot). Kenormalan residual $\hat{a}_{t}$ dapat dicirikan oleh histogram residual yang mendekati simetris atau plot probability normal yang menyebar di sekitar garis linier.

\subsection{Pemodelan TAR pada Data Mingguan Kurs Rupiah terhadap Dollar Amerika Serikat}

Ilustrasi pemodelan TAR dilakukan pada data mingguan kurs rupiah terhadap dollar Amerika Serikat periode 4 Oktober 2004 sampai dengan 7 Nopember 2011, sebanyak 370 pengamatan (http://www.ortax.org/).

a) Membuat Plot Data Mingguan Kurs

Berdasarkan Gambar 1., terlihat bahwa pada data mingguan kurs terjadi lonjakan secara tiba-tiba. Hal ini mengindikasikan bahwa data bersifat nonlinier.

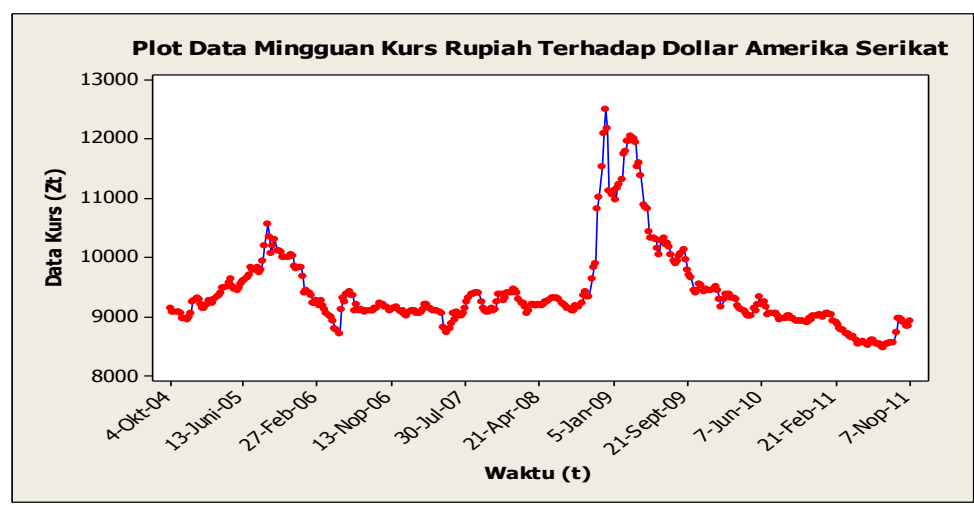

Gambar 1. Plot Data Mingguan Kurs 
b) Uji Nonlinier Menggunakan Uji Tsay

Berdasarkan uji Tsay, diperoleh $\hat{F}(p, d)=6,666$ dan nilai- $p=3,168 \times 10^{-19}$ sehingga asumsi linieritas ditolak sebab $\hat{F}(p, d)=6,666>F_{0,05 ; 311}=1,96822$ dan nilai- $p=3,168 \times 10^{-19}<\alpha=0,05$. Jadi, model bersifat nonlinier.

c) Identifikasi Model TAR, Estimasi Parameter Model TAR Menggunakan Metode OLS, dan Uji Signifikansi Parameter

Berdasarkan Tabel 1., diketahui bahwa nilai AIC minimum sebesar 4296. Dari nilai AIC minimum diperoleh nilai $d=1, p_{1}=2, p_{2}=2$, dan $r=9857$ sehingga data mingguan kurs mengikuti model TAR(2;2,2;1) dengan nilai threshold $r=9857$. Estimasi parameter model TAR pada regime 1 dan regime 2 dapat dilihat pada Tabel 2. dan Tabel 3. Berdasarkan Tabel 2. Dan Tabel 3., terlihat bahwa parameter model TAR untuk masing-masing regime, telah signifikan berbeda dengan nol sebab nilai- $p<\alpha$.

Tabel 1. Nilai AIC Untuk Parameter Delay $d$ dengan $1 \leq d \leq 7$

\begin{tabular}{|c|c|c|c|c|}
\hline $\begin{array}{c}\text { Delay } \\
(d)\end{array}$ & $\begin{array}{c}\text { Nilai } \\
\text { AIC }\end{array}$ & $\begin{array}{c}\text { Nilai Threshold } \\
(r)\end{array}$ & $\begin{array}{c}\text { Orde AR Regime 1 } \\
\left(p_{1}\right)\end{array}$ & $\begin{array}{c}\text { Orde AR Regime 2 } \\
\left(p_{2}\right)\end{array}$ \\
\hline 1 & 4296 & 9857,0 & 2 & 2 \\
\hline 2 & 4304 & 9674,0 & 2 & 2 \\
\hline 3 & 4310 & 9632,0 & 2 & 4 \\
\hline 4 & 4343 & 9343,6 & 2 & 4 \\
\hline 5 & 4373 & 9330,0 & 2 & 4 \\
\hline 6 & 4362 & 9417,6 & 3 & 4 \\
\hline 7 & 4386 & 9330,0 & 2 & \\
\hline
\end{tabular}

Tabel 2. Estimasi Parameter Model TAR $(2 ; 2,2 ; 1)$ pada Regime Pertama

\begin{tabular}{|c|c|c|c|c|}
\hline & Estimasi & Standard Error & $t_{\text {hitung }}$ & nilai- $p$ \\
\hline$\hat{\phi}_{0}^{(1)}$ & 308,5168 & 133,0267 & 2,3192 & 0,0201 \\
\hline$\hat{\phi}_{1}^{(1)}$ & 1,1944 & 0,0559 & 21,3774 & 0,0000 \\
\hline$\hat{\phi}_{2}^{(1)}$ & $-0,2280$ & 0,0553 & $-4,1223$ & 0,0000 \\
\hline
\end{tabular}


Tabel 3. Estimasi Parameter Model TAR $(2 ; 2,2 ; 1)$ pada Regime Kedua

\begin{tabular}{|c|c|c|c|c|}
\hline & Estimasi & Standard Error & $t_{\text {hitung }}$ & nilai- $p$ \\
\hline$\hat{\phi}_{0}^{(2)}$ & 850,2015 & 462,4364 & 1,8385 & 0,0710 \\
\hline$\hat{\phi}_{1}^{(2)}$ & 1,2907 & 0,1223 & 10,5550 & 0,0000 \\
\hline$\hat{\phi}_{2}^{(2)}$ & $-0,3706$ & 0,1212 & $-3,0578$ & 0,0033 \\
\hline
\end{tabular}

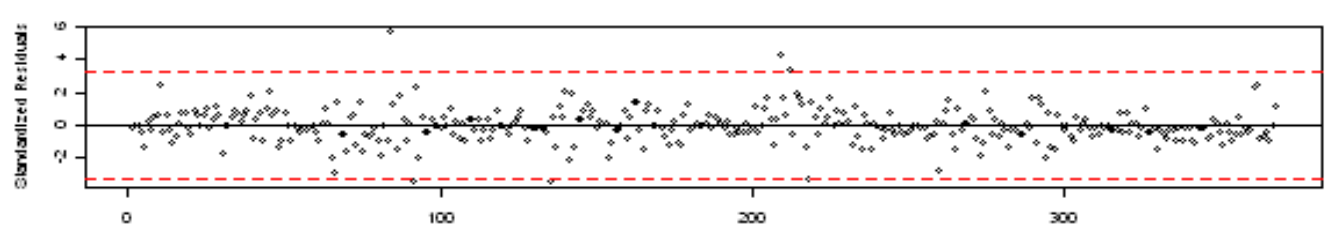

Gambar 2. Plot Residual Standar

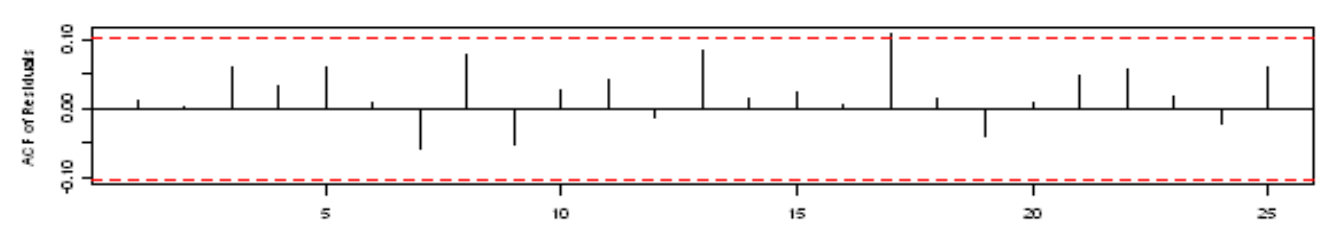

Gambar 3. Plot ACF Sampel Residual
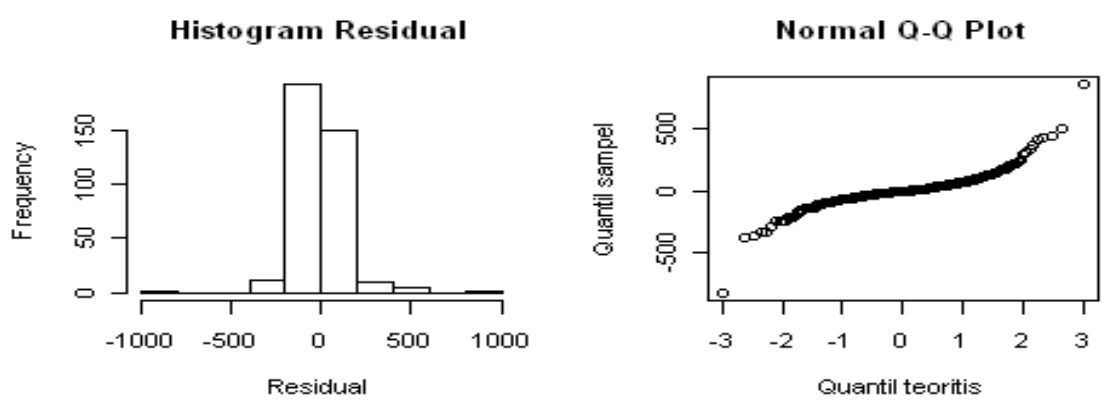

Gambar 4. Histogram Residual dan Plot Normal Probability (Q-Q plot) Untuk Residual Model TAR(2;2,2;1)

d) Uji Diagnostik

Berdasarkan Gambar 2., terlihat bahwa asumsi residual $\hat{a}_{t}$ mempunyai mean nol dan variansi konstan pada model sudah terpenuhi. Berdasarkan Gambar 3., terlihat bahwa 95\% nilai ACF sampel dari residual berada pada batas kritisnya, maka dapat disimpulkan bahwa residual $\hat{a}_{t}$ dan residual $\hat{a}_{t+k}$ tidak berkorelasi. Berdasarkan Gambar 4., terlihat bahwa histogram residual hampir simetris dan 
plot Normal Probability yang menyebar mendekati garis linier. Hal tersebut menunjukkan bahwa residual berdistribusi normal.

e) Model Terbaik

Model TAR terbaik untuk data mingguan kurs rupiah terhadap dollar Amerika Serikat periode 4 Oktober 2004 sampai dengan 7 Nopember 2011 adalah $\operatorname{TAR}(2 ; 2,2 ; 1)$ dengan nilai threshold $r=9857$ serta model pada regime pertama dan regime kedua sebagai berikut:

$$
Z_{t}= \begin{cases}308,5168+1,1944 Z_{t-1}-0,2280 Z_{t-2}+a_{t}^{(1)}, & \text { jika } Z_{t-1}<9857 \\ 850,2015+1,2907 Z_{t-1}-0,3706 Z_{t-2}+a_{t}^{(2)}, & \text { jika } Z_{t-1} \geq 9857,\end{cases}
$$

dengan $t \in\left\{p_{1}+1, \ldots, n\right\}$ untuk regime pertama dan $t \in\left\{p_{2}+1, \ldots, n\right\}$ untuk regime kedua sehingga $t \in\{3, \ldots, n\}$. Persamaan (8) menyatakan model TAR dua regime dengan nilai threshold $r=9857$ dan parameter delay $d=1$. Regime pertama dan regime kedua mengikuti model $\mathrm{AR}(2)$.

\section{KESIMPULAN DAN SARAN}

Berdasarkan hasil dan pembahasan, diperoleh kesimpulan sebagai berikut:

1. Pada penelitian ini telah dikaji bagaimana memperoleh estimator OLS untuk parameter model TAR, diperoleh $\hat{\boldsymbol{\varphi}}^{(j)}=\left(\mathbf{X}_{j}^{t} \mathbf{X}_{j}\right)^{-1} \mathbf{X}_{j}^{t} \mathbf{Z}_{j}$, untuk $j=1,2$.

2. Ada empat tahap dalam pemodelan TAR dua regime yaitu menguji keberadaan sifat nonlinier pada deret waktu menggunakan uji Tsay, mengidentifikasi model berdasarkan pendekatan AR tersusun dan AIC, mengestimasi parameter model TAR menggunakan metode OLS dan menguji kesignifikanan dari estimator OLS menggunakan uji $t$, serta uji diagnostik yang terdiri dari uji sifat white noise dan uji kenormalan pada residual.

3. Model TAR terbaik untuk data mingguan kurs rupiah terhadap dollar Amerika Serikat periode 4 Oktober 2004 sampai dengan 7 Nopember 2011 adalah TAR 
$(2 ; 2,2 ; 1)$ dengan nilai threshold $r=9857$, serta model pada regime pertama dan regime kedua sebagai berikut:

$$
Z_{t}=\left\{\begin{array}{l}
308,5168+1,1944 Z_{t-1}-0,2280 Z_{t-2}+a_{t}^{(1)}, \quad \text { jika } Z_{t-1}<9857 \\
850,2015+1,2907 Z_{t-1}-0,3706 Z_{t-2}+a_{t}^{(2)}, \quad \text { jika } Z_{t-1} \geq 9857,
\end{array}\right.
$$

dengan $t \in\{3, \ldots, n\}$.

Permasalahan terbuka yang dapat disarankan adalah:

1. Pengembangan penelitian untuk pemodelan TAR dengan orde lebih dari dua regime.

2. Pembahasan secara detail mengenai kajian uji nonlinieritas menggunakan uji Tsay, identifikasi model TAR berdasarkan pendekatan AR tersusun dan AIC, dan uji diagnostik.

\section{UCAPAN TERIMAKASIH}

Penulis pertama mengucapkan terima kasih kepada Dr. Nunung Nurhayati selaku Pembimbing Skripsi yang dengan penuh kesabaran telah memberikan waktu, ilmu dan motivasi kepada penulis.

\section{DAFTAR PUSTAKA}

Aswi dan Sukarna. (2006). Analisis Deret Waktu, Teori dan Aplikasi. Andira Publisher, Makassar.

Chan, W. S, Wong A. C. S. dan Tong, H. (2005). Some Nonlinear Threshold Autoregressive Time Series Models For Actuarial Use. North American Actuarial Journal, North American.

Cryer, J. D. dan Chan, K. C. (2008). Time Series Analysis With Applications in R. $2^{\text {nd }}$ Ed. Springer, New York.

Nuryana, F. (2009). Pemodelan Deret Waktu dengan Self Exciting Threshold Autoregressive (SETAR) dan Perubahan Struktur. Tesis. Institut Teknologi Sepuluh Nopember, Surabaya.

Observation and Research of Taxation. (2011). Kurs Menteri Keuangan Berdasarkan Mata Uang. http://www.ortax.org/. Diakses tanggal 7 Desember 2011.

Permata, M. I. (2008). Threshold Autoregressive Model of Exchange Rate PassThrough Effect in Indonesia. Working Paper. Bank Indonesia, Jakarta.. 